\title{
Investigation of Brucellosis Caused by Raw Goat Milk - Fujian Province, China, April-June, 2019
}

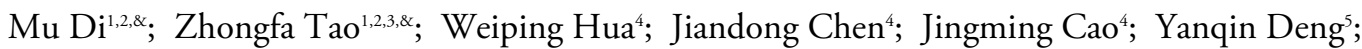 \\ Huihui Liu'; Lijie Zhang'; Yishan Chen ${ }^{6}$; Qiulan Chen'; Wenwu Yin ${ }^{1, *}$
}

\section{Summary \\ What is already known about this topic?}

Brucellosis is one of the most important zoonotic diseases in China. Goat milk and dairy products are essential pathways for foodborne transmission of brucellosis. Pasteurization can completely kill Brucella spp. in milk, and milk-borne transmission is mainly related to unhealthy dietary hygiene habits and insufficient epidemic control among animals.

\section{What is added by this report?}

This epidemic is the first outbreak of brucellosis in Zhangping City, Fujian Province. A total of 6 confirmed cases were found, and the onset time was from April to June 2019. The investigation suggested that the transmission chain of the epidemic included a private butcher, an infected goat from the north, a dairy farmer, close contact spread, unsterilized goat milk, and consumers drinking raw goat milk.

What are the implications for public health practices?

For the non-endemic area of brucellosis, preventing the import of infected animals and enhancing the practitioner's and the public's awareness of disease prevention has important public health significance. It is necessary to strengthen the transregional quarantine of livestock, the food safety inspection and management, and the practitioners' and public's awareness of food safety.

On July 3, 2019, Zhangping City reported an outbreak of brucellosis in a family cluster. The patients were a mother and a daughter (Patients I and II). Except for drinking goat milk produced and bottled from a local farmer, there was no other suspected exposure, so foodborne infection was highly likely. The city only reported 1 case of human brucellosis in 2011 (Yongfu County) and 1 case in 2017 (Heping County). Livestock were not routinely vaccinated against brucellosis. After the second reported case in 2017, the municipal-level agricultural department carried out a general investigation of brucellosis among livestock. The targeted prevention and control recommendations were put forward to determine the source of the epidemic and risk factors, and onsite investigations were carried out.

\section{INVESTIGATION AND RESULTS}

The suspected case definition was as follows: onset of patient illness occurred during the period from January 1 to July 3, 2019; residents of Zhangping City with fever, hyperhidrosis, muscle or joint pain, or fatigue; patient symptoms might be accompanied by liver, spleen, lymph nodes, testicular swelling, and other manifestations; and the rose Bengal test (RBT) result was positive. The confirmed case definition was as follows: a serum (tube) agglutination test (SAT) of titer $\geq 1: 100$; or a suspected case with isolated Brucella from the patient's blood, bone marrow, other body fluids, and excrement by bacterial isolation and culture. The recessive infection definition: RBT was positive but no clinical manifestations were detected.

Case searching was performed by acquiring case records, laboratory test reports, and interviews in local hospitals. Blood samples were taken from the dairy farmer (Mr. C) suspected of producing the goat milk that led to this outbreak, Mr. C's family members, and those who had drunk goat milk from Mr. C's farm between January 1 and July 3, 2019. In addition, further investigations were conducted into the hygiene habits of goat milk consumers; the breeding and quarantine of pigs, cattle, and goats in Zhangping City; the processing and supply of dairy products in Heping County; and sampling and quarantining the milk goats in Heping County.

If a RBT-positive person was found during the case search, the detailed demographic data, clinical data, eating habits, occupational history, preventive measures, and exposure history would be collected. If a patient had other suspected exposures, blood samples were tested to identify the source of infection. 
A total of 146 persons were sampled during the case search, and 6 confirmed cases were found. One of the blood specimens was cultured as Brucella ovis. All patients had symptoms of fatigue, 5 cases $(83 \%)$ were accompanied by fever, 2 cases (33\%) had hyperhidrosis and muscle aches, and 1 case $(17 \%)$ had vomiting, chills, and headache. There were no severe deaths or recessive infections. The male-to-female ratio was $1: 5$, including 3 workers, 2 unemployed houseworkers, and 1 student. The cases were from 4 households, all within the delivery scope of goat milk of Mr. C, and no other epidemiological association was found. Only one patient experienced onset of symptoms in April, and the remaining patients experienced onset from May 27 to June 12.

Except for Patient $V$ who was engaged in pig offal processing, the other patients' only suspected exposure was the raw goat milk (Table 1). The RBT test was negative for Patient V's coworkers and blood samples from the pig offal, which reduced the likelihood of transmission through pig offal processing. A total of 2 private farms in Zhangping City supplied fresh goat milk. Mr. C's dairy farm was a family workshop that did not abide by adequate sanitation measures, and 3 sampling specimens of Mr. C's dairy goats were positive for RBT (++++) while samples from the other dairy farm tested negative, confirming that the source of the infection was the dairy goats from $\mathrm{Mr}$. C's dairy farm.

This epidemic was the first outbreak of brucellosis among livestock in Zhangping City, and further investigations were needed to find the source of the infected dairy goat. The environmental investigation found that Mr. C's dairy farm was a closed iron goat pen so that the goat could not contact other animals.
Because Mr. C's goats did not have a quarantine certificate, the infected dairy goat was likely purchased by $\mathrm{Mr}$. C as the last quarantine record of a dairy goat he possessed was in 2014. Mr. C brought dairy goats twice: in 2016, 60 goats were purchased from a neighboring village in Zhangping City; and in 2017, an additional 2 dairy goats were purchased in Zhangping City from Mr. Y, one of which was likely the infected goat. The goats had been slaughtered and sold, and the relevant personnel's serum RBTs were all negative. The dairy goats were still maintained when the outbreak occurred. Mr. C stated that the goats had "slow growth and low milk production." One of the goats gave birth to lambs in early March 2019. The peak of infected milk lamb chops was after lambing (I) and combined with the case's onset date and the incubation period of brucellosis. It was speculated that Y's milk goat was the source of infection for this outbreak (Figure 1).

A retrospective epidemiological investigation into the goat producer Mr. Y showed that Mr. Y's goats had their first brucellosis case in Heping City on August 29, 2017. On August 1, 2017, Mr. Y bought 15 goats from a northern region (the specific source is unclear) and contracted brucellosis after slaughtering the goat with his bare hands with palms that had ruptured skin. During the local animal epidemic control department's investigation, Mr. Y had killed or sold most of the goats, and no brucellosis was detected in the remaining 3 dairy goats. During this investigation, Mr. Y admitted that he sold 2 goats to $\mathrm{Mr}$. C before culling by the animal husbandry department to reduce losses. Although the agricultural department carried out a general survey of brucellosis among livestock, his goat farm was not quarantined because Mr. C left the same day. The infected dairy goats were not found.

TABLE 1. Summary of cases in a brucellosis outbreak in Zhangping City, Fujian Province in 2019.

\begin{tabular}{|c|c|c|c|c|c|c|}
\hline \multirow{2}{*}{ Case number } & \multirow{2}{*}{ Suspected exposure } & \multirow{2}{*}{ Drinking method } & \multirow{2}{*}{ Onset date } & \multirow{2}{*}{ Main symptoms } & \multicolumn{2}{|c|}{ Lab results } \\
\hline & & & & & RBT & SAT \\
\hline I (index case) & Goat milk & $\begin{array}{l}\text { Warm bath }{ }^{*} \text { or direct } \\
\text { consumption }\end{array}$ & June 1 & Fever, sweating, fatigue & Positive & $1: 400$ \\
\hline II & Goat milk & $\begin{array}{l}\text { Warm bath or direct } \\
\text { consumption }\end{array}$ & June 3 & Fever, fatigue & Positive & $1: 400$ \\
\hline III & Goat milk & $\begin{array}{l}\text { Warm bath or direct } \\
\text { consumption }\end{array}$ & June 12 & Fever, vomiting, fatigue & Positive & $1: 400$ \\
\hline IV & Goat milk & Direct consumption & April 3 & Muscle aches, fatigue & Positive & $1: 100$ \\
\hline V & $\begin{array}{l}\text { Goat milk and } \\
\text { processing pork }\end{array}$ & Direct consumption & May 27 & $\begin{array}{l}\text { Fever, muscle aches, } \\
\text { sweating, fatigue }\end{array}$ & Positive & $1: 200$ \\
\hline VI & Goat milk & $\begin{array}{l}\text { Warm bath or Direct } \\
\text { consumption }\end{array}$ & June 10 & $\begin{array}{l}\text { Headache, fever, chills, } \\
\text { fatigue }\end{array}$ & Positive & $1: 800$ \\
\hline
\end{tabular}

Abbreviations: RBT=rose Bengal test; SAT=Serum agglutination test.

"Warm bath: warming up the milk to a suitable temperature by bathing it into warm water. 


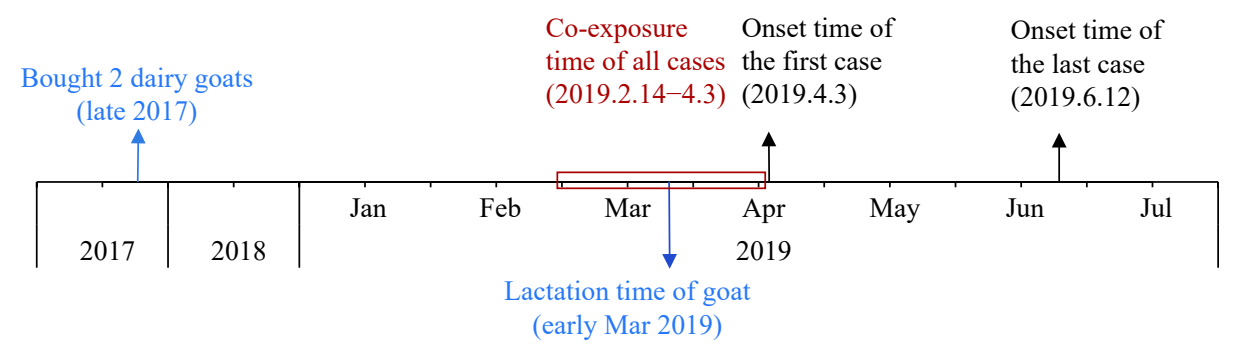

FIGURE 1. Timeline of the dairy farmer, Mr. C, purchasing the brucellosis-infected goats and the incidence of cases in the outbreak in Fujian Province, April-June, 2019.

\section{PUBLIC HEALTH RESPONSE}

All dairy goats in Mr. C's farm were culled and buried, and disinfection was conducted for the buildings. Medical institutions at all levels in Zhangping City were trained to strengthen diagnostic capabilities and brucellosis treatment. All goat breeders received health and hygiene education, and local farmers were trained on use of personal protection and the need for goat quarantine, especially to reduce incidence of brucellosis. Residents who consumed goat milk were recommended to monitor symptoms closely for an extended period after the outbreak.

\section{DISCUSSION}

In this outbreak investigation, importing an infected goat was the core link that likely caused the local brucellosis outbreak. In recent years, China's brucellosis disease burden had gradually spread from northern pastoral and semi-pastoral areas to southern non-pastoral regions (2-4). The main reason could be the increase in livestock trading between the north and south and increased private free-range livestock in the south. But the involved stakeholders' awareness and use of quarantine measures were relatively weak, causing an influx of infected animals and products from north to south (4). The investigation found that individual traders did not have compulsory quarantine measures in all aspects of purchasing, breeding, selling, and slaughtering livestock and their biological products. Practitioners had no incentive to submit them for inspection. Therefore, for non-endemic areas, preventing the import of infected animals and strengthening practitioners' and the general public's awareness for disease prevention has significant public health significance. The government should enhance the quarantine of transregional livestock transportation and local disease screening.
Because brucellosis symptoms in livestock are relatively hidden, outbreak control depends more on practitioners' active cooperation. The survey showed that the basic-level goat breeders' main paths for brucellosis prevention were veterinarians, traditional health education materials, and relatives and friends (5). Therefore, veterinary departments are encouraged to use their contact with goat breeders to strengthen practitioners' awareness of the effectiveness of quarantine measures for their livestock.

In recent years, food-borne brucellosis had repeatedly occurred in southern China (6-9). Contaminated dairy products were an important route of transmission of brucellosis (9-10). The interview found that residents in Zhangping City generally believed that raw milk products were more nutritious and were not aware of the possible health risks of raw milk products. As people's awareness of brucellosis was low, governments in low-risk areas should strengthen food safety inspections and management and raise the people's awareness of food safety.

This investigation was subject to some limitations. The local animal epidemic control department did not number when sampling and culling the dairy goat. During this investigation, the disease control agency could not obtain a quality sample from Mr. C's dairy goat. The quality of the blood sample available was poor, and the blood culture did not grow, so the animal disease control department could not obtain etiological evidence of infected dairy goat.

doi: $10.46234 / \mathrm{ccdcw} 2021.111$

\# Corresponding author: Wenwu Yin, yinww@chinacdc.cn.

\footnotetext{
${ }^{1}$ Chinese Center for Disease Control and Prevention, Infectious Diseases Management Office, Beijing, China; ${ }^{2}$ China Chinese Field Epidemiology Training Project, Beijing, China; ${ }^{3}$ Guizhou Provincial Center for Disease Control and Prevention, Guiyang, Guizhou, China; ${ }^{4}$ Zhangping County Center for Disease Control, Zhangping, Fujian, China; ${ }^{5}$ Fujian Provincial Center for Disease Control and Prevention, Fuzhou, Fujian, China; ${ }^{6}$ Emory University, Atlanta, USA.

\& Joint first authors.
}

Submitted: November 04, 2020; Accepted: April 14, 2021 


\section{REFERENCES}

1. Li RN, Shu C, Lei LX, Lei LX. Epidemiologic analysis and clinical manifestations of 38 children with brucellosis. Chin J Woman Child Health Res 2019;30(7):892 - 5. http://dx.doi.org/10.3969/j.issn.16735293.2019.07.028. (In Chinese).

2. Chen QL. Spatio-temporal analysis of brucellosis in my country and research on the quality of life related to patients' health [dissertation]. Beijing: Chinese Center for Disease Control and Prevention; 2017. http://cdmd.cnki.com.cn/article/cdmd-84501-1017118494.htm. (In Chinese).

3. Shi YJ, Lai SJ, Chen QL, Mu D, Li Y, Li XX, et al. Analysis on the epidemiological features of human brucellosis in northern and southern areas of China, 2015-2016. Chin J Epidemiol 2017;38(4):435 - 40. http://dx.doi.org/10.3760/cma.j.issn.0254-6450.2017.04.005. (In Chinese).

4. Lai SJ, Zhou H, Xiong WY, Yu HJ, Huang ZJ, Yu JX, et al. Changing epidemiology of human brucellosis, China, 1955-2014. Emerg Infect Dis 2017;23(2):184 - 94. http://dx.doi.org/10.3201/eid2302.151710.

5. Liu P, Zeng H, Liu CG, Wang JF, Gao L, Xu QG, et al. The situation and potentially influential factors of brucellosis awareness in occupational groups. Chin J Endemiol 2018;37(9):716 - 20. http://dx. doi.org/10.3760/cma.j.issn.2095-4255.2018.09.007. (In Chinese).

6. Xiang LH, Zhou WZ, Tang FY, Zhu YF, Tan ZM, Liu XY, et al. An outbreak of brucellosis in a village in Jiangsu province. Chin J Epidemiol 2014;35(10):1135 - 7. http://dx.doi.org/10.3760/cma.j.issn. 0254-6450.2014.10.013. (In Chinese).

7. Tian GZ, Cui BY, Zhao HY, Jiang H, Piao DR. Studies on epidemiology and molecular characteristics of Brucella melitensis during an outbreak of brucellosis. Dis Surveill 2017;32(3):211 - 5. http://dx. doi.org/10.3784/j.issn.1003-9961.2017.03.011. (In Chinese).

8. Qin QC, Li ZJ, Chen XQ, Zhao SY, Cheng GH, Cui BY. Epidemiological investigation of an outbreak of brucellosis caused by drinking of unpasteurized ewe's milk in Hezhou of Guangxi. Dis Surveill 2018;32(8):634 - 7. http://dx.doi.org/10.3784/j.issn.10039961.2017.08.006. (In Chinese).

9. Pappas G, Papadimitriou P, Akritidis N, Christou L, Tsianos EV. The new global map of human brucellosis. Lancet Infect Dis 2006;6(2):91 9. http://dx.doi.org/10.1016/S1473-3099(06)70382-6.

10. Franco MP, Mulder M, Gilman RH, Smits HL. Human brucellosis. Lancet Infect Dis 2007;7(12):775 - 86. http://dx.doi.org/10.1016/ S1473-3099(07)70286-4. 